\title{
FEASIBILITY OF THE UNDERGROUND EARTHQUAKE BRACELET
}

\author{
AMAL GERGES \& NABIL FARES \\ Department of Civil Engineering, University of Balamand, Lebanon
}

\begin{abstract}
Earthquakes are sudden phenomena that occur worldwide and have the potential to cause significant devastation. A number of methods have emerged over the years in an effort to decrease their destructive potential, including the emergence of seismic design, dampening mechanisms and shock absorbents. The earthquake bracelet is a new solution which entails digging a gap around a building and then engineering the fill as well as the basement floors to provide more desirable behavior under earthquake load. A dynamic analysis study was completed to explore the response of the structure and assess the feasibility of the idea. Many cases were explored to identify the change in the response spectrum with and without the earthquake bracelet. The results of the preliminary study have been encouraging and indicate that the method is feasible and can be conceptualized as utilizing underground stories and their surroundings as a sophisticated base-isolation system. In order to accomplish this, the system must have: (i) a flexible bracelet, (ii) relatively flexible underground stories and (iii) preferably, a higher relative mass of understructure over superstructure is preferred.
\end{abstract}

Keywords: earthquake bracelet, dynamics of structure, base isolation, earthquake, understructure, preservation, preliminary study.

\section{INTRODUCTION}

Lebanon, a Mediterranean country situated astride the Dead Sea Transform, has experienced a number of major earthquakes over its history. The most recent major event occurred on the 25th of November 1759 impacting Beirut and Damascus and resulting in more than 40,000 fatalities. Prior to this, earthquakes had not been considered in building design. More recently, earthquake design has become mandatory prerequisite for construction permits, and buildings have been designed as situated in a $2 \mathrm{c}$ seismic zone such that the seismic zone factor is $Z=0.25$ (which represents the peak ground acceleration in studied site as a percentage of gravity acceleration $\left.\mathrm{g}\left(9.81 \mathrm{~m} / \mathrm{s}^{2}\right)\right)$.

If an earthquake having a magnitude close to that of the 1759 event were to happen today, it would be a national catastrophe. A few minutes of earthquake could cause damage equivalent to 16 years of war. Thus, it may be necessary to retrofit existing buildings, prioritizing essential buildings such as schools and hospitals due to the probable expense.

Hopefully, this study will show that a decrease in the earthquake effect is achievable and can be reasonably implemented on some critical existing structures.

Try the following: Obtain a mug, a plastic water bottle and cotton wool. Place the water bottle on top and then put a layer of cotton wool around the bottle between the mug and the bottle. Hold the mug by its handle and vibrate it. Now compare by vibrating the bottle directly. Do you notice the difference? The bottle vibrates much more when you directly move it. This is what our study resembles.

\subsection{Background on isolation systems of buildings}

The first application of seismic isolation took place in Japan and the United States during the early 1980s. As a demonstration project in 1982 Japan built an isolated structure, which was a small house. Likewise, in 1985 in the US, the first isolated building was a county 
administration building in Southern California [1]. Cooperation between scientists in Japan, New Zealand and the US took place throughout the 1980s, resulting in advancement in both the technology of seismic isolation and passive energy dissipation. As Japan's economy boomed, New Zealand and the US couldn't keep up, and funding for such projects came via government-mandated research investment for construction companies [1], [3].

Recently base isolators and damping devices have been more commonly used. Base isolation is used to decouple the structure from the foundation lying on the ground, which enhances the structure's earthquake resistance.

There are many types of base isolation systems such as elastomeric bearings, friction pendulum bearings, rollers and ball bearings.

Now damping devices are able to absorb energy in order to reduce the structure's response to earthquake. They can be combined with the base isolators or placed in diagonal braces along the height of the structure. They can also be applied for tall buildings that can't be properly base-isolated [2], [4].

\subsection{Scope of work}

The response spectrum is often used in building design to mitigate the impact of potential harmonic ground motion or earthquakes. With this approach, the periods of the first few modes of vibration of the building are determined and the corresponding maximum displacements are then obtained from the response spectrum. These maximum displacements with their corresponding mode shapes are used to identify the maximum loading cases and their impacts are combined appropriately. By having an underground mass hugged by an isolating polymer with the mass of superstructure above it, the response spectrum is altered which modifies the maximum loading conditions. There are parameters associated with this isolation system and with the variation of these parameters we get a response spectrum family a.k.a. response spectra. In this study we are investigating whether there are some combinations of parameters that lead to a significant beneficial improvement in the effective response spectrum.

\section{MODEL AND REVIEW OF RESPONSE SPECTRA}

\subsection{Model}

First, we isolate the underground mass with a material of a certain thickness and depth (Fig. 1). This eliminates the side forces in an earthquake and thus creates an isolated underground mass with a certain stiffness; the superstructure above it also has a certain stiffness and mass [5].

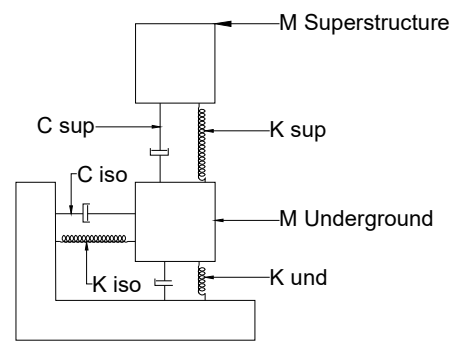

Figure 1: Basic model. 
From the model depicted in Fig. 1, we obtain the following equations of motion:

$$
\begin{gathered}
{\left[\begin{array}{cc}
M_{\text {und }} & 0 \\
0 & M_{\text {sup }}
\end{array}\right]\left[\begin{array}{l}
U^{\prime \prime}{ }_{\text {und }} \\
U^{\prime \prime} \text { sup }
\end{array}\right]+\left[\begin{array}{cc}
K_{\text {iso }}+K_{\text {sup }}+K_{\text {und }} & -K_{\text {sup }} \\
-K_{\text {sup }} & K_{\text {sup }}
\end{array}\right]\left[\begin{array}{l}
U_{\text {und }} \\
U_{\text {sup }}
\end{array}\right]+} \\
{\left[\begin{array}{cc}
C_{\text {iso }}+C_{\text {sup }}+C_{\text {und }} & -C_{\text {sup }} \\
-C_{\text {sup }} & C_{\text {sup }}
\end{array}\right]\left[\begin{array}{c}
U^{\prime}{ }_{\text {und }} \\
U_{\text {sup }}^{\prime}
\end{array}\right]} \\
=\left[\begin{array}{c}
K_{\text {iso }} \times U_{g}+K_{\text {und }} \times U_{g}+C_{\text {iso }} \times U_{g}^{\prime}+C_{\text {und }} \times U_{g}^{\prime} \\
0
\end{array}\right],
\end{gathered}
$$

such that:

- $M_{\text {und }}$ : Underground mass in $\mathrm{kg} ; M_{\text {sup }}$ : Mass of superstructure in $\mathrm{kg}$.

- $K_{\text {und }}$ : Stiffness of the underground structure in $\mathrm{KN} / \mathrm{m} ; K_{\text {sup }}$ : Stiffness of the superstructure in $\mathrm{KN} / \mathrm{m} ; K_{\text {iso: }}$ : Stiffness of isolation in $\mathrm{KN} / \mathrm{m}$.

- $C_{\text {und }}$ : Damping of the underground structure in $\mathrm{KN} \times \mathrm{s} / \mathrm{m} ; C_{\text {sup }}$ : Damping of the superstructure in $\mathrm{KN} \times \mathrm{s} / \mathrm{m}$; $C_{i s o}$ : Damping of the isolation in $\mathrm{KN} \times \mathrm{s} / \mathrm{m}$.

- $U_{\text {und }}$ : Displacement of the underground in m; $U_{\text {sup }}$ : Displacement of the superstructure in $\mathrm{m}$; $U$ ' und: Velocity of the underground in $\mathrm{m} / \mathrm{s} ; U_{\text {sup }}$ : Velocity of the superstructure in $\mathrm{m} / \mathrm{s}$; $U^{\prime}$ ' ${ }_{\text {und }}$ : Amplitude of the underground in $\mathrm{m} / \mathrm{s}^{2} ; U^{\prime \prime}$ sup: Amplitude of the superstructure in $\mathrm{m} / \mathrm{s}^{2}$.

- $U_{g}$ : Ground motion displacement in $\mathrm{m} ; U_{g}^{\prime}$ : Ground motion velocity in $\mathrm{m} / \mathrm{s} ; U^{\prime}{ }_{g}$ : Ground motion amplitude in $\mathrm{m} / \mathrm{s}^{2}$.

To simplify the equations, let:

$$
U_{n 1}=U_{\text {und }}-U_{g} \text { and } U_{n 2}=U_{\text {sup }}-U_{g}
$$

having:

$$
\begin{gathered}
\text { Mund } \times U^{\prime \prime} \text { und }+\left(K_{\text {iso }}+K_{\text {sup }}+K_{\text {und }}\right) \times U_{\text {und }}-K_{\text {sup }} \times U_{\text {sup }}=K_{\text {iso }} \times U_{g}+K_{\text {und }} \times U_{g} \\
M_{\text {sup }} \times U_{\text {sup }}-K_{\text {sup }} \times U_{\text {und }}+K_{\text {sup }} \times U_{\text {sup }}=0 .
\end{gathered}
$$

The equations become the following:

$$
\begin{gathered}
M_{\text {und }} \times U^{\prime}{ }_{n 1}+M_{\text {und }} \times U^{\prime}{ }_{g}+\left(K_{\text {iso }}+K_{\text {sup }}+K_{\text {und }}\right) \times U_{n 1}-K_{\text {sup }} \times U_{n 2}+2 K_{\text {sup }} \times U_{g}=0 \\
M_{\text {sup }} \times U^{\prime}{ }_{n 2}-M_{\text {sup }} \times U{ }^{\prime}{ }_{g}+K_{\text {sup }}\left(U_{n 2}-U_{n 1}\right)=0
\end{gathered}
$$

\subsection{What are response spectra and what is their role in design}

In earthquake engineering the response spectra are very useful in quantifying the ground motion and the building's ability to resist earthquakes. The design response spectrum (RS) plots the displacement of a single degree of freedom system, with varying natural frequencies, resulting from a forced motion (base vibration). We expand this definition to allow Multiple Degrees Of Freedom (MDOF) where we consider the RS of a main Degree Of Freedom (DOF) with other DOFs considered as internal variables or parameters. More clearly, instruments distributed and located in several locations sense the initial ground motion of an earthquake and data about the ground motion are thus collected over time. The first data reported is the peak ground acceleration data (PGA). The PGA provides information over the intensity of the ground motion, but it doesn't provide information concerning the 
response of buildings with different periods. Now if the peak acceleration, displacement or velocity is calculated when an earthquake hits for several systems of different stiffness $\mathrm{K}$ and mass $\mathrm{M}$, the locus of point plotted will form the response spectrum. Therefore, if the period of vibration is known, the elements of design required can be deduced [6].

\subsection{Estimating mass, stiffness and damping of various classes of buildings}

For the sake of accuracy and in order to obtain the proper ratio of masses and stiffness for each mode of movement during earthquake of the building, a model must be analyzed. The effective masses (percentage of modal mass) are needed in order to identify which mode can be readily excited by base excitation and to see whether the masses are to be used as they are, or as a certain percentage only. The same goes for the stiffness. To that end and as an example, we have collected information concerning hospitals.

Using the data in Table 1, a six-story building with two underground basements, having the masses equivalent to the average of masses collected in the hospital's survey was modeled on Etabs software where the results are presented in Tables 2 and 3. Two Etabs files were created: one with only the superstructure, and the other including only the underground basements. After running the models, the ratio of modal masses was extracted from the Etabs reports. For the superstructure, see Table 2. For the underground, see Table 3.

Table 1: Hospital data.

\begin{tabular}{|l|c|c|c|c|c|c|c|}
\hline $\begin{array}{l}\text { Hospital/ } \\
\text { country }\end{array}$ & $\begin{array}{c}\text { Built up } \\
\text { area m }^{2}\end{array}$ & $\begin{array}{c}\text { Area } \\
\text { of sup }\end{array}$ & $\begin{array}{c}\text { \# of } \\
\text { sup }\end{array}$ & $\begin{array}{c}\text { Area } \\
\text { of und }\end{array}$ & $\begin{array}{c}\text { \# of } \\
\text { und }\end{array}$ & $\begin{array}{c}\text { Sup } \\
\text { weight }\end{array}$ & $\begin{array}{c}\text { Und } \\
\text { weight }\end{array}$ \\
\hline \multirow{2}{*}{ CMC-Dubai } & 45,000 & 2,800 & 5 & 5,300 & 4 & 37,824 & 60,844 \\
\cline { 2 - 9 } & & 1,900 & 3 & & & & \\
\hline \multirow{3}{*}{ CMC-Riyadh } & 62,000 & 2,200 & 6 & 6,000 & 5 & 62,784 & 86,100 \\
\cline { 2 - 9 } & & 1,900 & 8 & & & & \\
\cline { 2 - 9 } & & 1,700 & 2 & & & & \\
\hline CMC-Lebanon & & 900 & 1 & & & & \\
\hline \multirow{2}{*}{ CMC-Amman } & 80,000 & 4,000 & 8 & 1,600 & 6 & 36,736 & 27,552 \\
\cline { 2 - 9 } & & 900 & 35 & & & & \\
\hline
\end{tabular}

Table 2: Table of modal participating mass ratios part 1.

\begin{tabular}{|l|c|c|c|c|c|c|c|c|}
\hline Case & Mode & Period sec & Ux & Uy & Uz & Sum Ux & Sum Uy & $\begin{array}{c}\text { Sum } \\
\text { Uz }\end{array}$ \\
\hline Modal & 1 & 0.763 & 0.016 & 0.4963 & 0 & 0.0016 & 0.4963 & 0 \\
\hline Modal & 2 & 0.597 & 0.0184 & 0.2375 & 0 & 0.02 & 0.7338 & 0 \\
\hline Modal & 3 & 0.527 & 0.6638 & 0.0022 & 0 & 0.6838 & 0.7361 & 0 \\
\hline Modal & 4 & 0.212 & 0.0003 & 0.126 & 0 & 0.6841 & 0.8621 & 0 \\
\hline Modal & 5 & 0.159 & 0.0016 & 0.0349 & 0 & 0.6856 & 0.897 & 0 \\
\hline Modal & 6 & 0.117 & 0.2023 & 0 & 0 & 0.8881 & 0.942 & 0 \\
\hline Modal & 7 & 0.106 & 0.0001 & 0.0451 & 0 & 0.8885 & 0.9443 & 0 \\
\hline Modal & 8 & 0.075 & 0.0004 & 0.0023 & 0 & 0.8885 & 0.9443 & 0 \\
\hline
\end{tabular}


Table 3: Table of modal participating mass ratios part 2.

\begin{tabular}{|l|c|c|c|c|c|c|c|}
\hline Case & Mode & $\mathrm{Rx}$ & $\mathrm{Ry}$ & $\mathrm{Rz}$ & $\mathrm{SUM} \mathrm{Rx}$ & SUM Ry & SUM Rz \\
\hline Modal & 1 & 0.11942 & 0.0006 & 0.2376 & 0.1942 & 0.0006 & 0.2376 \\
\hline Modal & 2 & 0.0913 & 0.0085 & 0.461 & 0.2854 & 0.0092 & 0.6987 \\
\hline Modal & 3 & 0.0008 & 0.3286 & 0.0186 & 0.2862 & 0.3378 & 0.7173 \\
\hline Modal & 4 & 0.3491 & 0.0006 & 0.0362 & 0.6353 & 0.3384 & 0.7534 \\
\hline Modal & 5 & 0.0883 & 0.0027 & 0.1378 & 0.7236 & 0.341 & 0.8912 \\
\hline Modal & 6 & $5.462 \mathrm{E}-06$ & 0.3618 & 0.0018 & 0.7236 & 0.7028 & 0.893 \\
\hline Modal & 7 & 0.1067 & 0.0002 & 0.009 & 0.8303 & 0.7031 & 0.9021 \\
\hline Modal & 8 & 0.0046 & 0.001 & 0.0558 & 0.8349 & 0.7041 & 0.9579 \\
\hline
\end{tabular}

It was concluded that no reduction of mass or stiffness is necessary and therefore examples of the study can proceed using the whole masses without using contribution factors.

\section{RESPONSE SPECTRA IN THE EARTHQUAKE BRACELET AND NON-DIMENSIONALISATION}

\subsection{The 1-DOF response spectra and how it changes in the earthquake bracelet model}

In a 1-DOF function where $u g[t]$ is a sinusoidal function, such that $u_{g}[t]=a m p \times \sin (w t)$, if $u g$ is replaced in the equation of motion:

$$
f(u)=m \times u^{\prime},[t]+c \times u^{\prime}[t]+k \times u[t]=-k \times u_{g}[t],
$$

such that $\mathrm{t}$ varies from 0 to tmax, the parameters of the equation become: $\mathrm{m}, \mathrm{c}, \mathrm{K}, \mathrm{amp}, \mathrm{w}$, $\mathrm{u}_{0}, \mathrm{v}_{0}, \mathrm{t}_{\max }$.

The period $\mathrm{T}$ of the structure is then defined in function of both parameters $\mathrm{m}$ and $\mathrm{K}$, afterwards $\mathrm{K}$ is expressed as a function of $\mathrm{m}$ and $\mathrm{T}$. Now we are able to plot the displacement in function of $\mathrm{t}$ for a specific period and the maximum value of the displacement $\mathrm{u}$ after steady state is extracted.

We are then able to plot the maximum of $u \rightarrow U_{\max }$ for a range of $T$. Having the plot of $\mathrm{U}_{\max }$ in function of the period, we have thus the response spectrum. Now how does this apply to the model of the Earthquake Bracelet? Our model is based on a 2-DOF equation where we have $U_{\text {und }}$ and $U_{\text {sup }}$, for the understructure mass and superstructure respectively, the superstructure mass has a stiffness and damping which we associate with the first mode of the superstructure. The understructure mass has two sets of stiffnesses and damping coefficients, the first set corresponds to the bracelet while the second to the foundation below the understructure mass. The parameters to be manipulated are: $M_{\text {und }}, M_{\text {sup }}, K_{\text {und }}, K_{\text {sup }}, C_{\text {und }}$, $\mathrm{C}_{\text {sup }}, \mathrm{K}_{\text {iso }}, \mathrm{C}_{\text {iso. }}$. Thus, the response spectra will be manipulated as functions of a range of all the parameters. The effect of the initial conditions $\mathrm{U}_{01}, \mathrm{~V}_{01}, \mathrm{U}_{02}$ and $\mathrm{V}_{02}$ are removed by considering only the long time response and neglecting transitions. Finally, the earthquake period $\mathrm{T}_{\text {eq }}$ is used as a normalization factor.

This allows us to know for a structure, having a specific ratio of mass, what is the $\mathrm{K}_{\text {iso, }}$, among other design parameters, needed to retrofit the structure, by fixing the masses and manipulating $K_{\text {iso }}$ to get the response spectrum with lowest peak $(\rightarrow$ lowest displacement amplification). 


\subsection{The non-dimensionalization of the equations}

Usually the response spectrum is a family of curves that depends on the natural damping of the building, but in our case it also depends on additional parameters. We want to reduce the number of parameters involved in order to more efficiently search the parameter space for beneficial behavior. To that end we resort to non-dimensionalization and we propose non-dimensionalized parameters that are more easily understood.

Since the response spectrum is our stepping stone, a program using Mathematica was written. An data inputs, the ratio of mass of the braceleted ground over that of the superstructure ( $\left.\mathrm{mR}=\mathrm{M}_{\mathrm{und}} / \mathrm{M}_{\text {sup }}\right)$, the ratio of periods where it is the period of the underground mass over that of the earthquake $\left(\mathrm{TR}_{\text {und }}=\mathrm{T}_{\text {und }} / \mathrm{T}_{\mathrm{eq}}, \mathrm{TR}_{\mathrm{iso}}=\mathrm{T}_{\mathrm{iso}} / \mathrm{T}_{\mathrm{eq}}\right)$ and damping ratios of the superstructure, understructure and isolation $\left(\zeta_{\text {sup }}=\mathrm{c}_{\text {sup }} /\left(2 \mathrm{~m}_{\text {sup }}\left(2 \pi / \mathrm{T}_{\text {sup }}\right)\right), \zeta_{\text {und }}=\mathrm{c}_{\text {und }} /\left(2 \mathrm{~m}_{\text {und }}\right.\right.$ $\left.\left.\left(2 \pi / \mathrm{T}_{\text {und }}\right)\right), \zeta_{\text {iso }}=\mathrm{c}_{\text {iso }} /\left(2 \mathrm{~m}_{\text {und }}\left(2 \pi / \mathrm{T}_{\text {iso }}\right)\right)\right)$ shall be entered to generate the desirable response spectrum output. This will allow us to identify and manipulate the parameters while seeing the behavior of the response spectrum allowing us to draw conclusions concerning each manipulation of parameter, or group of parameters.

Forcing function: $\mathrm{u}_{\mathrm{g}}=\mathrm{A} \times \sin \left[2 \pi \times \mathrm{t} / \mathrm{T}_{\mathrm{eq}}\right]$, all displacements are non-dimensionalized by the amplitude of the earthquake: A that we chose as one unit of length.

First equation:

$$
\begin{aligned}
& -4 \pi^{2} \operatorname{Usup}[\tau]+4 \pi^{2} \operatorname{Uund}[\tau]+\frac{4 \mathrm{mR} \pi^{2} \mathrm{TR} \sup ^{2} \operatorname{Uund}[\tau]}{\operatorname{TRiso}^{2}}+\frac{4 \mathrm{mR} \pi^{2} \mathrm{TR} \sup ^{2} \operatorname{Uund}[\tau]}{\text { TRund }^{2}}-
\end{aligned}
$$

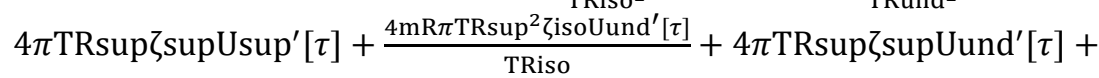

$$
\begin{aligned}
& \frac{4 \mathrm{mR} \pi \mathrm{TRsup}^{2} \zeta \text { undUund }^{\prime}[\tau]}{\text { TRund }}+\text { mRTRsup }^{2} \text { Uund }^{\prime \prime}[\tau]=\frac{8 \mathrm{mR} \pi^{2} \mathrm{TRsup}^{2} \zeta \text { isoCos }[2 \pi \tau]}{\text { TRiso }}+ \\
& \frac{8 \mathrm{mR} \pi^{2} \mathrm{TRsup}{ }^{2} \zeta \text { und } \operatorname{Cos}[2 \pi \tau]}{\text { TRund }}+\frac{4 \mathrm{mR} \pi^{2} \mathrm{TRsup}^{2} \operatorname{Sin}[2 \pi \tau]}{\text { TRiso }^{2}}+\frac{4 \mathrm{mR} \pi^{2} \mathrm{TRsup}^{2} \operatorname{Sin}[2 \pi \tau]}{\mathrm{TRund}^{2}} .
\end{aligned}
$$

Second equation:

$$
\begin{aligned}
& 4 \pi^{2} \operatorname{Usup}[\tau]-4 \pi^{2} \operatorname{Uund}[\tau]+4 \pi \mathrm{TRsup} \operatorname{supUsup}^{\prime}[\tau]- \\
& 4 \pi \mathrm{TR} \operatorname{Rup} \zeta \operatorname{supUund}[\tau]+\operatorname{TRsup}^{2} \operatorname{Usup}^{\prime \prime}[\tau]=0 .
\end{aligned}
$$

\section{COMPUTER METHOD AND IMPLEMENTATION}

\subsection{Solution procedure}

During the study of the solution of the non-dimensionalized earthquake bracelet equations, an obstacle was encountered. While exploring the graphs presented in Fig. 2 and while manipulating the masses and period of the equation, we couldn't have clear oversight over the system's behavior, for when a change positively affected the superstructure it at times negatively affected the under structure and vice versa.

Therefore, in order to be more precise and to understand clearly the behavior of the system we proceeded to find the response spectrum and explore it.

\subsection{Implementation (mathematica file description)}

After non-dimensionalizing the equations as previously shown, we proceeded to manipulate the plot of the solutions with various ranges for parameters such as $\mathrm{TR}_{\text {sup }}, \mathrm{mR}, \mathrm{TR}_{\text {und }}$ and $\mathrm{TR}_{\mathrm{iso}}$ between 0.1 and 10 , while damping ratios $\zeta_{\text {sup }}$, $\zeta_{\text {und }}$ and $\zeta_{\text {iso }}$ are at 0.05 varying between 0 and 1 , the earthquake period ranges from 0.1 to $5 \mathrm{sec}$ and $\mathrm{u}_{\max }$ at 2 varying as a power of 2 . 


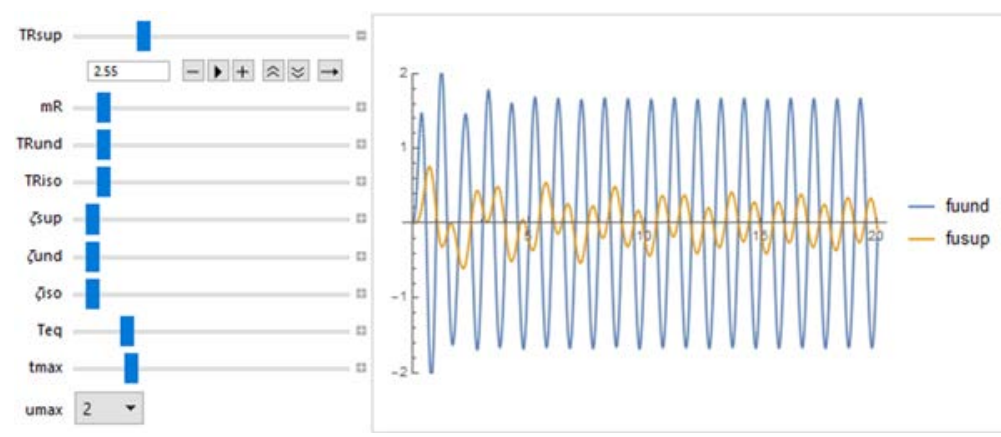

Figure 2: Solution of the equation of motion.

As mentioned in Section 4.1, the manipulation of this plot in Fig. 2 didn't lead to clear conclusions and it was hard to correlate between the two graphs. Thus, the response spectrum of the earthquake bracelet was plotted with the same previous ranges with the sole modification of dividing the earthquake period by the period of the superstructure. Afterwards a combination between the system's original response spectrum and one with an earthquake bracelet present was written with parameters varying as the following $\mathrm{mR}, \mathrm{TR}_{\text {und }}$ and $\mathrm{TR}_{\text {iso }}$ from 0.1 to a max of 5 , the damping ratios of the isolation, superstructure and understructure vary from 0 to 1, and then the following plots in Fig. 3 were generated. (Green RS: building without EQ bracelet; red RS: building with EQ bracelet).

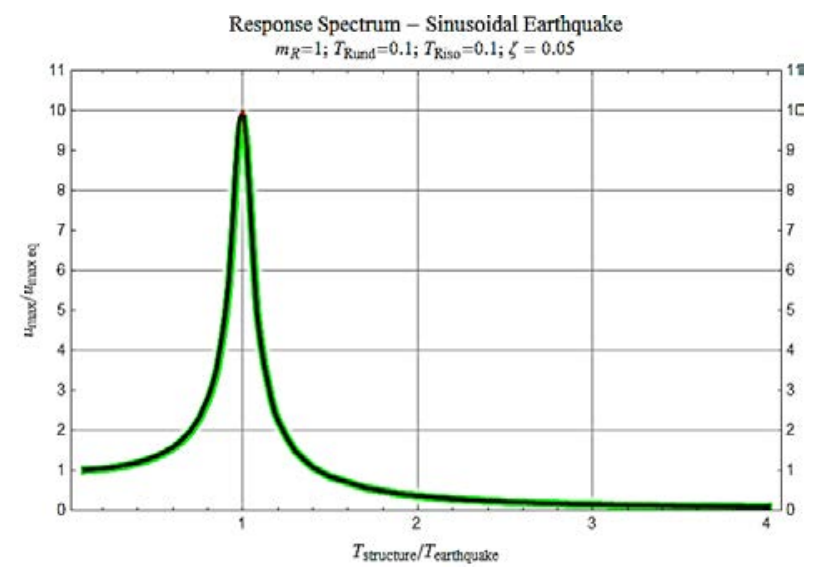

Figure 3: Combination of Response Spectra $\left(\mathrm{U}_{\max } / \mathrm{U}_{\max \text { eq }}\right.$ in function of $\left.\mathrm{T}_{\text {structure }} / \mathrm{T}_{\text {earthquake }}\right)$.

\section{PARAMETRIC STUDIES}

\subsection{Range of systems considered}

In our trials and exploration of the graph implemented on Mathematica, we initially have the response spectrum of the regular Single Degree Of Freedom (SDOF) matching that of the earthquake bracelet since we have $\mathrm{TR}_{\text {und }}$ and $\mathrm{TR}_{\text {iso }}$ at 0.1 both. 
Many cases were observed, varying, of the many cases a few will be discussed, and conclusions will follow. The cases vary between the very bad and the very good. Firstly, we studied the effect of $\mathrm{mR}$ on the system by fixing the periods of the superstructure and the understructure at 2 .

We managed to observe in the graphs generated, for which Fig. 4 is an example, that for $\mathrm{mR}=1$ as well as $\mathrm{mR}=2, \mathrm{mR}=3$ the bracelet has hugely decreased the amplitude of the response spectra. The application of the bracelet is encouraging and we could better understand its characteristics through manipulating the parameters and exploring the graphs. Another approach that could help better understand the observation is when the mass ratio is fixed and the periods manipulated to be able to compare more easily.

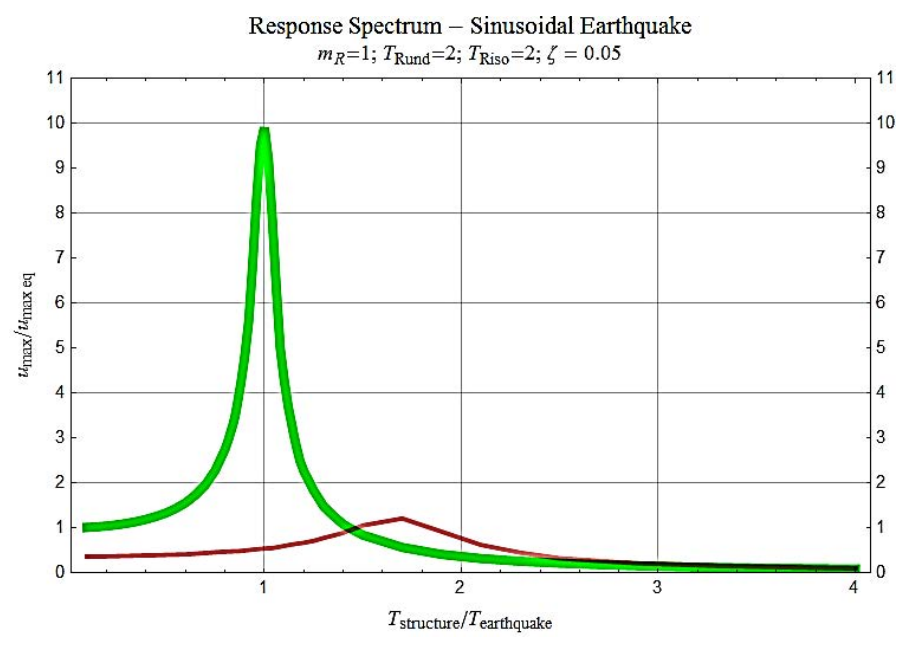

Figure 4: Response Spectra for $\mathrm{mR}=1$ and period ratios equal 2.

\subsubsection{For $\mathrm{mR}=0.5$}

The meaning of $\mathrm{mR}=0.5$ is that the mass of the understructure is half the mass of the superstructure; we observed some of the best matches for this mass ratio such as, $\mathrm{TR}_{\mathrm{und}}=1$ and $\mathrm{TR}_{\text {iso }}=2, \mathrm{TR}_{\text {und }}=1$ and $\mathrm{TR}_{\text {iso }}=2.5, \mathrm{TR}_{\text {und }}=0.85$ and $\mathrm{TR}_{\text {iso }}=3, \mathrm{TR}_{\mathrm{und}}=0.9$ and $\mathrm{TRiso}=3$.

In Fig. 5 where $\mathrm{TR}_{\text {iso }}$ is 2 we notice that the resonance has disappeared completely and the low displacements either decreased or remained the same. When increasing $\mathrm{TR}_{\text {iso }} 2.5$ and 3 respectively we notice that it almost remains the same as for 2 . Furthermore, increasing $\mathrm{TR}_{\text {und }}$ to 0.9 still produces a significant decrease in the resonance.

\subsubsection{For $\mathrm{mR}=1$}

For a high period of isolation such that $\mathrm{TR}_{\text {iso }}$ fixed to $3 \mathrm{~s}$, $\mathrm{TR}_{\text {und }}$ varied between $1,2,2.5$ and 3 (Fig. 6).

\subsubsection{For $\mathrm{mR}=1.5$}

For a fixed value of $\mathrm{TR}_{\text {und }}=3$ such as $\mathrm{TR}_{\mathrm{und}}=3$ and $\mathrm{TR}_{\text {iso }}=2, \mathrm{TR}_{\mathrm{und}}=3$ and $\mathrm{TR}_{\text {iso }}=2.5, \mathrm{TR}_{\mathrm{und}}=3$ and TRiso $=3$. As all previous cases the response spectrum is enhanced when the isolation's flexibility increases, as Fig. 7 illustrates. 


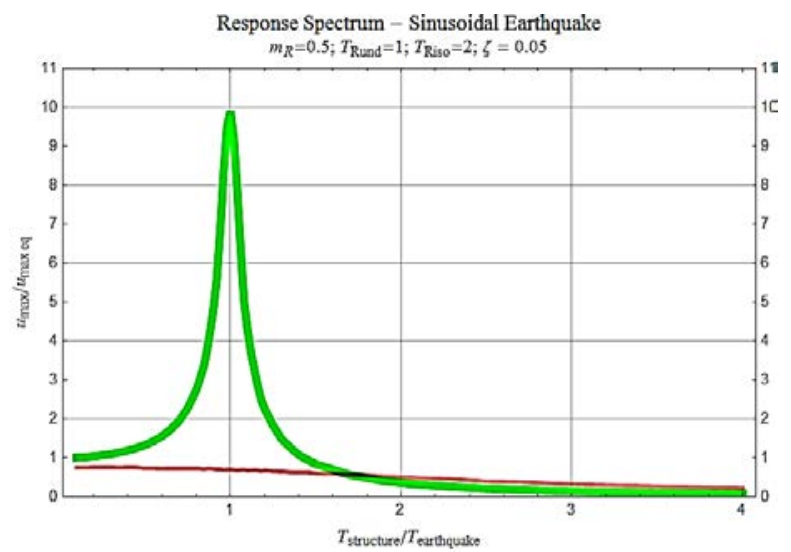

Figure 5: Response Spectra for fixed $m R=0.5, \mathrm{TR}_{\text {und }}=1$ and $\mathrm{TR}_{\text {iso }}=2$.

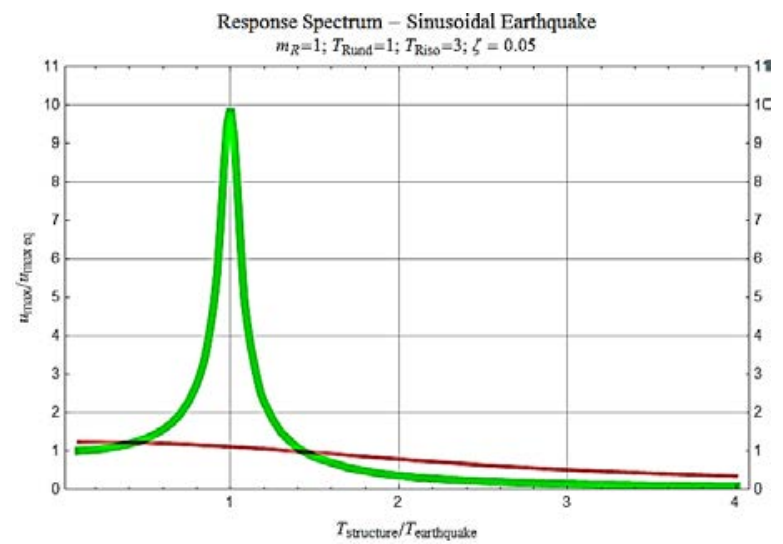

Figure 6: Response spectra for fixed $m R=1, \mathrm{TR}_{\text {und }}=1$ and $\mathrm{TR}_{\mathrm{iso}}=3$.

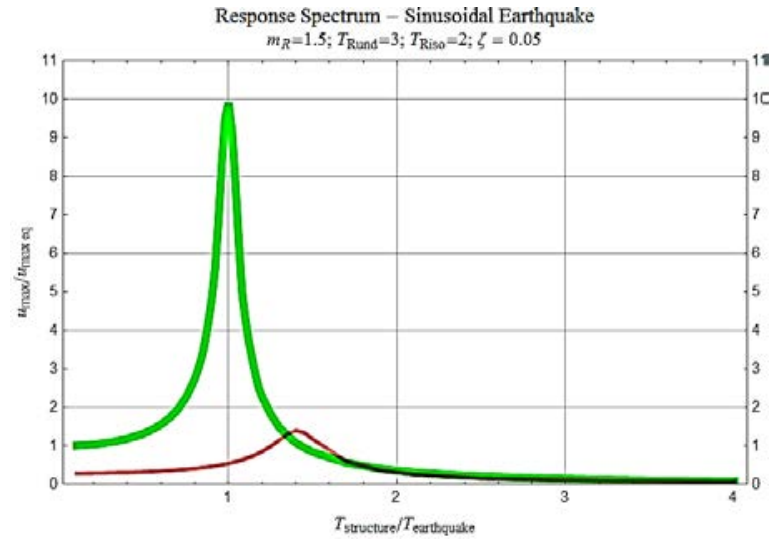

Figure 7: Response Spectra for $\mathrm{mR}=1.5$ fixed, $\mathrm{TR}_{\mathrm{und}}=3$ and $\mathrm{TR}_{\text {iso }}=2$. 
PII-118 Earthquake Resistant Engineering Structures XII

\subsubsection{For $\mathrm{mR}=2$}

We observed bad matches except for high periods such as, $\mathrm{TR}_{\text {und }}=0.8 \rightarrow 3$ and $\mathrm{TR}_{\text {iso }}=0.8 \rightarrow 3$ (Fig. 8).

\subsubsection{For $\mathrm{mR}=3$}

The bad cases are the following: $\mathrm{TR}_{\mathrm{und}}=1$ and $\mathrm{TR}_{\mathrm{iso}}=2, \mathrm{TR}_{\mathrm{und}}=1.5$ and $\mathrm{TR}_{\mathrm{iso}}=1$ the uncertain case is the following: $\mathrm{TR}_{\mathrm{und}}=3$ and $\mathrm{TR}_{\text {iso }}=1.5$.

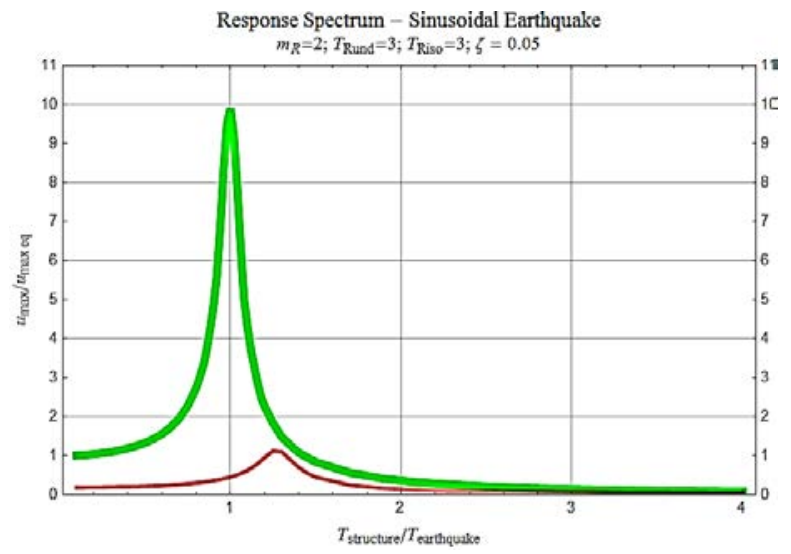

Figure 8: Response Spectra for $\mathrm{mR}=2$ fixed, $\mathrm{TRund}=3$ and TRiso $=3$.

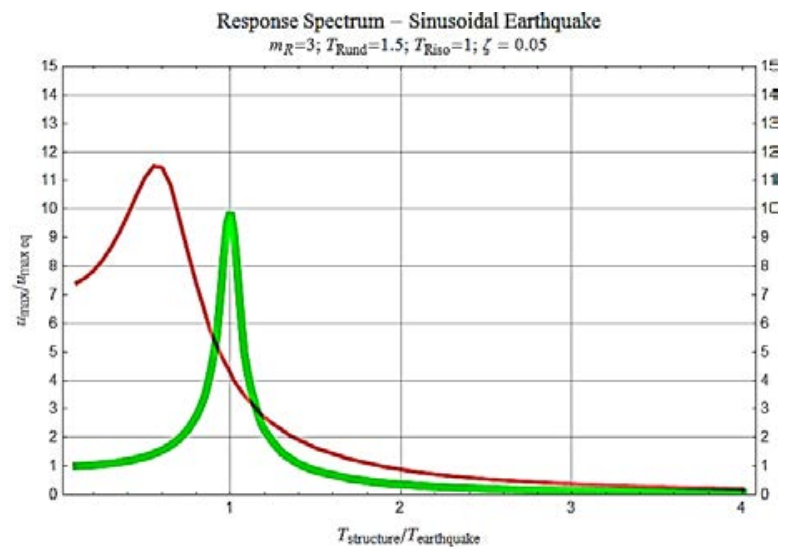

Figure 9: Response Spectra for $\mathrm{mR}=3$ fixed, $\mathrm{TRund}=1$ and TRiso $=2$.

In Fig. 9, the response spectrum became much worse versus a scenario with no earthquake bracelet.

For $\mathrm{TR}_{\mathrm{und}}=3$ and $\mathrm{TR}_{\text {iso }}=1.5$ there was a reduction in the value of the displacement but also an increase in the low displacements which creates uncertainty.

The good matches occurred for high periods of substructure and isolation for $\mathrm{mR}=3$ fixed, $\mathrm{TR}_{\mathrm{und}}=2.5$ and $\mathrm{TR}_{\text {iso }}=3, \mathrm{TR}_{\mathrm{und}}=3$ and $\mathrm{TR}_{\text {iso }}=2, \mathrm{TR}_{\mathrm{und}}=3$ and $\mathrm{TR}_{\text {iso }}=3$. The graphs generated all resemble the one in Fig. 9. 


\subsection{Interpretation of results}

After close interpretation of the above graphs, the enhancement of the RS occurred for a high period of isolation and a high period of understructure, meaning the more flexible the isolation and underground structure is, the more the displacements are decreased (as can be seen in Figs 6-8). Moreover, we observe that a high mass ratio (mass of understructure larger than that of the superstructure) with a flexible underground mass enhances greatly the results. We can also deduce that results are enhanced when the understructure is half the mass of the superstructure and has a period relatively close to that of the earthquake $\left(\mathrm{TR}_{\mathrm{und}}=1 \mathrm{which}\right.$ means $\left.\mathrm{T}_{\text {und }} / \mathrm{T}_{\mathrm{eq}}=1\right)$.

On the other hand, keeping a larger mass of understructure relatively flexible is tricky. More thought needs to be given to achieve the desired decrease in the response spectrum in cases with a larger mass of understructure while maintaining flexibility or rendering it even more flexible (high $\mathrm{T}_{\text {und }}$ ) needs to be given more thought to come up with ways that help in order to get the required decrease in the response spectrum.

An overall interpretation is that by using the earthquake bracelet we are actually transforming the underground stories into a complex base isolation system. This would be consistent with our results indicating that the understructure must be as heavy and as flexible as possible, as this is precisely the profile of a base isolation layer.

\section{CONCLUSIONS}

The hypothesis and exploration in this report is a preliminary study. In order to proceed further in the study and to provide a pathway for further development, some conclusions and recommendations are presented:

- The preliminary study is encouraging and indicates that the method is feasible.

- The concept can be conceptualized as utilizing underground stories and their surroundings as a sophisticated base-isolation system.

- To have the understructure behave as a base-isolation system, we require (i) a flexible bracelet, (ii) relatively flexible underground stories and (iii) preferably, higher relative mass of understructure over superstructure.

Our recommendations for further study are as follows:

- This study looked at the superstructure and substructure as each being a single mass. This would not capture possible mode interactions between multiple superstructure modes and multiple substructure modes. In future, we propose segmenting both the superstructure and substructure to investigate this further.

- We need to investigate the response spectra under multiple types of earthquakes, both real and simulated, and not just due to a sinusoidal applied ground motion.

- Find methods to implement the design implications on the bracelet and the substructure. Specifically, how to make a well-supporting bracelet while being highly flexible and energy absorbent perhaps by studying several types of elastomers (their dampening characteristics and flexibility) and how to make a relatively heavy yet flexible underground, such a system may be implemented.

- Designing example buildings to verify the calculations in a full setting.

- Experimental explorations using shake tables and model buildings.

- The Earthquake Bracelet should also be considered in regularly designing buildings against earthquake loads and not just for retrofitting. In particular, this approach may be very significantly cost effective and simple relative to other options. 


\section{REFERENCES}

[1] Kelly, J., Base Isolation in Japan: 1988 (No. UCB/EERC-88/20), Earthquake Engineering Research Center, University of California at Berkeley, 1998.

[2] Clark, P., Aiken, D., Nakashima, M., Miyazaki, M. \& Midorikawa, M., The 1995 Kobe earthquake as a trigger for implementing new seismic design technologies in Japan. Lessons Learned Over Time, Learning From Earthquakes, vol. III, Earthquake Engineering Research Institute, 1999. www.siecorp.com/lfe/index.html.

[3] Buchanan, A.H., Bull, D., Dhakal, R., MacRae, G., Palermo, A. \& Pampanin, S., A report written for the royal commission of inquiry into building failure caused by the Canterbury earthquakes (No. 2011-02), University of Canterbury, 2011.

[4] Seismic Isolation Engineering, Inc., Database of U.S. Seismically Isolated Buildings. Unpublished manuscript, 1999.

[5] De la Cruz, S.T., Rodríguez, M.A. \& Hernández, V., Using Spring-Mass Models to Determine the Dynamic Response of Two-Story Buildings Subjected to Lateral Loads, Autonomous University of Ciudad Juárez, 2012.

[6] Earthquake-response spectra, Fundamental of Vibration (pp. 53). Lecture based on Chopra, A.K. (ed)., Earthquake response of linear systems. Dynamics of structures, Theory and Applications to Earthquake Engineering, 3rd ed., Pearson, p. 197, 2006. 